\title{
Comunicación y democracia
}

Las reflexiones siguientes están relacionadas directamente con la lectura del libro Comunicación altemativa y sociedad civil*, sobre el cual su editor-compilador me pidió hacer un comentario. A lo largo del libro son recurrentes tres temas, cuya importancia es central en el debate sociopolítico contemporáneo, tanto en El Salvador como en el conjunto de América Latina: (a) el problema de la democracia; (b) el problema de la comunicación, y (c) el problema de las relaciones entre democracia y comunicación.

1. El problema de la democracia. El debate sobre la democracia, por más que se hayan aportado al mismo infinidad de tesis e ideas, todavía no está cerrado. $\mathrm{Y}$ no está cerrado porque la democracia, como régimen político, no se agota en la competencia electoral, el pluralismo ideológico o la alternancia en la gestión del aparato estatal. Sin duda alguna, esos aspectos son claves para el ordenamiento democrático de la sociedad, pero no basta con ellos para hablar de una democracia política consolidada.

Un régimen político democrático requiere, además de los elementos apuntados, de dos cosas adicionales: en primer lugar, de una cultura política democrática; es decir, de la vigencia de una mínima ética cívica anclada en las reglas y los valores de la democracia. Para ello es necesario que los miembros de la sociedad -no sólo las élites dirigentes - hayan interiorizado aquellas reglas y valo- res, especialmente en todo lo que apunta al reconocimiento de los propios derechos y deberes, el respeto a las leyes, el respeto al otro (en tanto que distinto) y la tolerancia. Sin la vigencia de un ethos democrático, esto es, sin el anclaje de la democracia en el mundo de la vida cotidiana, la misma no será más que un ritual cuyos oficiadores - los políticos- serán los únicos interesados en mantener y reproducir, siempre y cuando les reditúe en beneficios personales o de grupo.

En segundo lugar, un régimen político democrático requiere de la participación activa de la sociedad civil, participación que no se reduce a la elección de un gobiemo (sea local o nacional), sino que debe canalizarse a través de todas las instancias que la hagan posible: opinión pública, cabildos abiertos, actividades comunitarias, etc. Para esto, obviamente, es clave el fortalecimiento de los grupos intermedios de la sociedad: escuelas, centros de discución cultural, ONG's... Por supuesto, no se trata de defender $\longrightarrow$ de proponer- la participación de todos en todo; ello, además de ser teóricamente insostenible, es absolutamente irrealizable en la práctica

Si cada uno de los habitantes de una sociedad tuvieran que participar en todas las decisiones que se toman para sacarla adelante. el resultado serfa la parálisis gubernamental. A pesar de que esto es una verdad inobjetable, lo contrario no es totalmente

* Ayala Ramírez, Carlos (Ed.-Comp.), Comunicación altemativa y sociedad civil, San Salvador, Fundación Konrad Adenauer, 1997. 


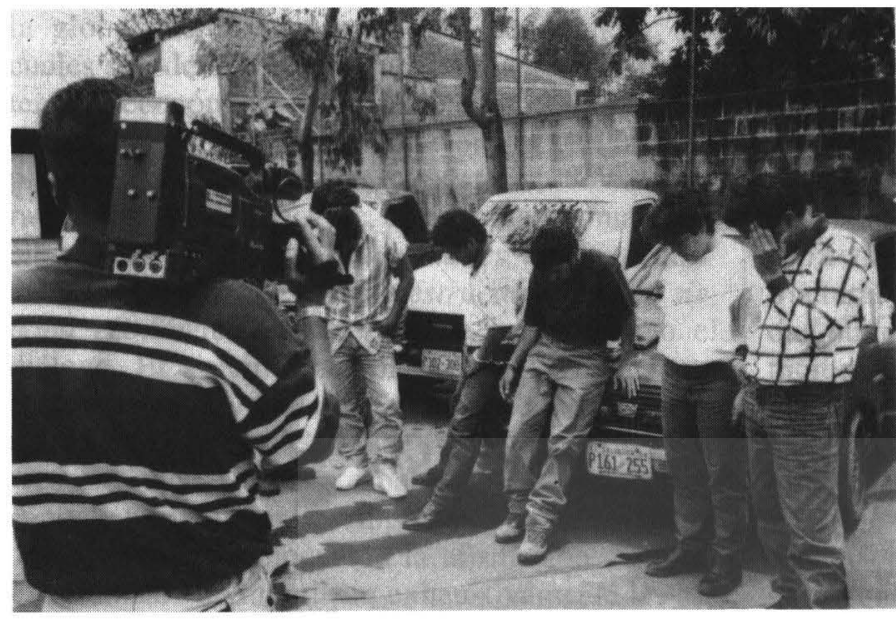

un día para otro; es necesario un largo esfuerzo de ciudadanización, en el cual desempeñan una función importante el sistema educativo, los medios de comunicación, la promoción y divulgación científica y artística, la creación de espacios de discusión cultural a lo largo y ancho del país.

Todavía no nos hemos tomado en serio la construcción de una ciudadanía. Y esta no puede lograrse sin la creación de una cultura política democrática, cuyo desarrollo en El Salvador es aún incipiente. Ha llegado el momento de dejar de promocionar a los políticos; se trata, ahora, de promocionar culturalmente a la sociedad civil: de educarla no sólo para

cierto: es decir, que lo mejor para la marcha de una sociedad es que sus miembros participen lo menos posible en las decisiones que se toman. Para eso, se nos dice, están los especialistas de la economía y la política, quienes son los que mejor "saben" cuáles son las necesidades de un país y cuál es el modo de resolverlas.

Un recto planteamiento de la democracia no puede aceptar la tesis de concentración absoluta de las decisiones en manos de los "especialistas". Si bien acepta que todos no pueden participar en todo, acepta también que los "especialistas" suelen cometer más desmanes de lo debido, desmanes a los que sólo puede poner paro una sociedad civil con capacidad de incidir en determinados ámbitos del quehacer político y económico. En otras palabras, la sociedad civil debe contar con espacios de participación específicos que permitan no sólo mayor eficacia en la ejecución de las políticas gubernamentales - con lo que se superaría el peligro de una parálisis gubernamental-, sino una fiscalización de las actividades de los que técnica, política y económicamente son responsables de conducir una nación.

En El Salvador, desde la firma de la paz, hemos avanzado bastante en la dimensión político-electoral de la democracia. Sin embargo, hemos avanzado más bien poco o casi nada en la consolidación de una cultura político democrática. Pesa bastante todavía, en la mentalidad de los salvadoreños, la herencia autoritaria. Nos cuesta aceptar que tenemos deberes no sólo con nuestros parientes y amigos cercanos, sino con cualquier miembro de la sociedad, sea hombre o mujer, niño o anciano, creyente o increyente, homosexual o lesbiana.. Ciertamente, una cultura política democrática no se construye de vivir en democracia, sino para que cada uno de los individuos que la constituyen defiendan, promuevan y reproduzcan en su vida cotidiana los valores y reglas de la democracia.

Poco hemos avanzado también en la participación de la sociedad civil. Aquí no hay que obviar el recuerdo, en la memoria colectiva, de la violencia que se ejerció sobre los sectores populares en las décadas de los setenta y ochenta. Con todo, un obstáculo importante para la participación de la sociedad civil son sus suficientes niveles organizativos. Sin las instancias organizativas adecuadas, la sociedad civil salvadoreña no podrá encauzar sus demandas en la dirección requerida y, peor aún, no podrá participar constructiva y creativamente en la solución de sus problemas más acuciantes. El auge sin precedentes de la organización popular de la década de los setenta es sólo un recuerdo de glorias pasadas. Nadie dice que el estilo organizativo de los noventa tiene que calcarse de la época heróica del movimiento popular salvadoreño; más aún, las pretensiones de calcar aquella experiencia, por su anacronismo, terminarían haciendo más mal que bien a la sociedad y al país. Sin embargo, la formación de unas instancias organizativas que encausen las energías de la sociedad civil es una necesidad imperiosa en la actual fase de la instauración democrática.

En definitiva, la construcción orden democrático supone no sólo crear los mecanismos institucionales para que las elecciones periódicas, la competencia partidaria y la diversidad ideológica sean una realidad, sino sentar las bases sociales, educativas e informativas para la creación de una cultura política democrática que anime la participación de la socie- 
dad civil, la solución de los problemas particulares de sus miembros y los problemas nacionales más urgentes. Una vez que se ha avanzado bastante sobre lo primero, ha llegado el momento de prestar la debida atención a los otros dos aspectos de la democracia: la cultura política democrática y la participación-organización de la sociedad civil. En la solución de los desafíos que estas dos realidades plantean se juega el futuro de la democracia en El Salvador.

2. El problema de la comunicación. En nuestro país, el problema de la comunicación es en verdad grave. Las comunicaciones ocupan un espacio decisivo en la vida de los habitantes, pero la gran mayoría de salvadoreños hemos sido convertidos en meros "consumidores pasivos" de las informaciones, la publicidad y los estilos de vida que los medios de comunicación cotidianamente difunden. Los medios pueden difundir - y de hecho difunden - las opiniones más disparatadas en materia política y económica; pueden también promover - y de hecho promueven- proyectos políticos abanderados por los grupos de derecha... Y, prácticamente, no hay forma de sustraerse de su influjo. Los gestores de la publicidad e información lo saben, y actúan en consecuencia: nos someten, rigiéndose por criterios de marketing y de conveniencia política, a una lluvia de productos informativos y publicitarios ante los cuales nada se puede hacer.

Es decir, en El Salvador se ha configurado una lógica comunicativa unidireccional, que va de los medios hacia un público receptor, el cual importa exclusivamente en cuanto a consumidor de los "productos" promovidos por las corporaciones televisivas, la prensa escrita o la radio y sus principales clientes de la industria, las finanzas o el comercio. En un escenario de este tipo, lo que predomina es la distorsión comunicativa en cuanto que la manipulación mercadotécnica se vuelve la regla de oro de los que establecen y realizan las políticas de comunicación. Si a ello se añaden los vínculos económicos e ideológicos de las grandes corporaciones de medios de comunicación con los sectores políticos de derecha, la manipulación de la opinión pública se vuelve un elemento básico de las estrategias de los grupos de poder en El Salvador. Sobran ejemplos para ilustrar el compromiso político de los grandes medios de comunicación: el último de ellos es la campaña promocional para presentar a Francisco Flores, precandidato de ARENA, como el político ideal que va a redimimos de la decadencia política.
En resumen, en la actualidad, es prácticamente imposible sustraerse al influjo de los medios de comunicación; gran parte de nuestra vida, nuestras elecciones, opiniones y valoraciones son moldeadas por los mismos. Sin embargo, los medios no han sabido $\longrightarrow$ no han querido- utilizar este influjo para forjar ciudadanos responsables, críticos y conscientes de sus derechos y deberes, sino simples consumidores pasivos de los bienes que ellos promueven. Es, pues, urgente un replanteamiento del papel de los medios de comunicación en nuestro país. Este replanteamiento debe tener como horizonte la consolidación democrática.

3. El problema de las relaciones entre comunicación y democracia. Un orden democrático requiere, entre otras cosas, de la participación ciudadana. Ahora bien, esa participación puede tener distintas modalidades, una de las cuales es la participación en la elaboración, difusión y promoción de la información. Es decir, la participación activa en el proceso de comunicación. La lógica comunicativa dominante - por reducir a los ciudadanos a meros receptores pasivos de la información y la publicidad- imposibilita que la sociedad civil, sus miembros y organizaciones, puedan desempeñar un rol más protagónico en las comunicaciones.

Ello constituye un serio obstáculo para el avance de la democracia en el país, puesto que la democratización de las comunicaciones es un aspecto esencial para encauzar la participación ciudadana en una dirección crítica y creativa. El esfuerzo que están haciendo las radios comunitarias por mantenerse en el aire constituye, en este sentido, un esfuerzo notable para democratizar las comunicaciones. Es un esfuerzo que merece el repaldo de todos los salvadoreños. Es una veta que conviene explorar creativamente.

El libro Comunicación alternativa y sociedad civil es, como parte de ese empeño por dar voz a los que no tienen voz, el primer intento serio por dar cuenta, reflexivamente y con rigor analítico, de los supuestos y retos de la comunicación alternativa en El Salvador. Es urgente que nuevos esfuerzos sigan a éste. Es urgente que todos nos tomemos en serio la tarea de pensar en formas alternativas de comunicación que permitan no sólo abrir espacios de participación a la sociedad civil, sino posicionarse críticamente ante el papel que los grandes medios de comunicación desempeñan en la actualidad.

Luis Armando González 